\title{
Aspectos da reconstituição da dialética em Ruy Fausto*
}

\author{
Aspects of the reconstitution of dialectics in Ruy Fausto
}

\author{
Renata Guerra \\ renataguerra@usp.br \\ (Universidade de São Paulo, São Paulo, Brasil) \\ Bruno Serrano \\ bruno.klein@usp.br \\ (Universidade de São Paulo, São Paulo, Brasil)
}

Resumo: 0 artigo pretende examinar alguns aspectos do programa de reconstituição da dialética perseguido por Ruy Fausto em sua interpretação do pensamento de Marx. Para tanto, apresentamos brevemente, na primeira parte, elementos da formação desse programa na vertente frankfurtiana da assim chamada Neue Marx-Lektüre, iniciada em meados dos anos 1960, esforço ao qual Fausto associa seu projeto teórico. Na segunda parte, discutimos três características de sua reconstituição da dialética, a saber: o lugar da metafísica na teoria do capitalismo, a função da contradição e o processo de interversão da liberdade. No fim, sugerimos que, com tal conceito de interversão, o programa de Fausto pretendia se abrir ao campo do vivido, procurando assim religar lógica e prática política.

Palavras-chave: Marx; lógica dialética; crítica da economia política; teoria do valor.
Abstract: The article aims to examine some aspects of the program of reconstitution of dialectics pursued by Ruy Fausto in his interpretation of Marx's thought. Firstly, it briefly presents the elements of the formation of this program in the Frankfurtian strand of the so-called Neue Marx-Lektüre, initiated in the mid-1960s, an effort to which Fausto associates his theoretical project. Secondly, it discusses three features of his reconstitution of dialectics, namely the position of metaphysics in the theory of capitalism, the function of contradiction, and the freedom interversion process. Finally, it is suggested that through such a concept of interversion Fausto's program aimed to open itself up to the field of the lived experience, thus seeking to reconnect logic and political practice.

Keywords: Marx; dialectical logic; critique of political economy; value theory.

\footnotetext{
* Renata Guerra (processo 17/03781-4) e Bruno Serrano (processo 17/03780-8) agradecem à Fundação de Amparo à Pesquisa do Estado de São Paulo (FAPESP).
} 


\section{Neue Marx-Lektüre e o programa de reconstrução da teoria do valor de Marx}

No primeiro tomo de Marx: lógica e política ${ }^{1}$, Ruy Fausto enunciava o sentido em que seus estudos sobre Marx e a dialética devem ser entendidos. Ele diz que os ensaios daquele volume e dos que o sucederiam "representam o ponto de partida, diríamos, decalcando uma expressão que não é nossa, que se trata [...] de apresentar os 'materiais para uma reconstrução da dialética'” (MLP I, p.15). Com isso, ele reivindicava para seus escritos uma orientação programática que floresceu e amadurecia sobretudo na Alemanha (especialmente no lado ocidental). Nesse sentido, Fausto (idem, p.22) menciona os três primeiros ensaios seminais da série em quatro partes intitulada "Materiais para a reconstrução da teoria do valor de Marx", de autoria de Hans-Georg Backhaus, para sinalizar o alinhamento de sua pesquisa. ${ }^{2}$ De fato, passava-se então por uma vaga reconstrutiva. Portanto, quando ele fala em reconstituição e reconstrução, reconhecendo que a "expressão [se] deve assim a muita gente" (idem, ibidem), tratava-se de estabelecer a filiação do seu projeto não tanto a esta ou aquela posição e interpretação particulares, mas antes de tudo a um diagnóstico geral do estado da teoria e a um programa de pesquisa. Sobre esta nossa sugestão, cabem algumas observações preliminares.

Quando falamos em programa de pesquisa, não queremos dar a entender uma coincidência de interpretações e da seleção particular dos textos e manuscritos de Marx para o projeto de reconstituição. Essa aproximação às vezes implica concordância com teses específicas, por exemplo, quando Fausto (MLP I, p.128, nota 21) escreve "que H. G. Backhaus acentua com razão a ligação entre a teoria do valor e a teoria do dinheiro" em Marx - na visão de Ingo Elbe (2010, p.67), a característica mais distintiva da vertente frankfurtiana da Neue Marx-Lektüre. Mas é evidente que ela não exclui divergências, de teor e amplitude, no interior daquele programa. É preciso ter em mente a pluralidade de posições das novas leituras alemãs em sentido lato, das quais os trabalhos de Backhaus e Helmut Reichelt representam uma corrente, ligada ao círculo da teoria crítica do Instituto de Pesquisa Social, como mostraram

1 Os três tomos de Marx: lógica e política serão referidos como "MLP", seguido do número do tomo e da paginação.

2 Esse alinhamento não significa que o próprio Fausto seguisse exclusivamente esses debates alemães, nem tampouco que suas reflexões e interesses simplesmente decalcassem posições naqueles debates. O alinhamento sugerido por nós indica, antes, um compartilhamento de certas preocupações lógicas, uma convergência de certas linhas de força. Indício desse alinhamento, Fausto faz questão ainda de se referir ao artigo de Wolfdietrich Schmied-Kowarzik intitulado "Para a reconstrução da dialética materialista", publicado no número 11 da revista teórica Gesellschaft, em 1978. No esclarecimento da origem da Neue Marx-Lektüre frankfurtiana, Backhaus (1997, p.216, nota 111) se refere ao círculo de trabalho formado junto ao Instituto de Ciência Política na Universidade de Frankfurt, ao qual pertencia a maioria dos editores daquela revista. Esse grupo procurava, ainda segundo o autor, ler de uma nova forma, a partir de outra problemática, os escritos de Marx, principalmente O capital. No final das contas, é o próprio Fausto (ver MLP I, p.15) que levanta a associação de seu projeto àqueles esforços de reconstrução da teoria dialética marxiana que se haviam iniciado em meados dos anos 1960 na Alemanha. 
Elbe (2010, pp.66-87) e Jan Hoff (2009, pp.78-94). ${ }^{3}$

Assim, por exemplo, quando Backhaus e Reichelt (1995) criticam o que consideram ser uma interpretação nominalista da abstração real por parte de Michael Heinrich, ou quando este critica a prevalência que o conceito de "capital em geral" (tão central para aqueles) adquire nas interpretações da crítica da economia política madura de Marx (Heinrich, 1999 [1991], pp.185-189) - em que também está em questão tanto o peso que se dá a textos e manuscritos diferentes quanto o papel da filosofia de Hegel -, dificilmente se poderia supor que Backhaus, Reichelt e Heinrich não compartilhassem elementos de um programa de pesquisa. ${ }^{4}$ De modo que, quaisquer que sejam as diferenças no interior do diagnóstico geral das deficiências da teoria (que de fato variam), em todo caso se convergia em que ela não ia bem e era preciso retrabalhá-la. Pelo menos é assim que se entende o próprio Heinrich (2004, p.27) quando, referindo-se a Backhaus e Reichelt e ao "novo ímpeto" que deram "à nova leitura de Marx", afirma que, apesar das diferenças, o "presente trabalho também se insere no contexto substantivo dessa "nova leitura de Marx'”. Como notou Hoff (2009, p.176) em seu abrangente estudo do estado da pesquisa internacional em torno de Marx, a discussão realizada por Fausto sobre a categoria do trabalho abstrato e o problema da dialética na relação entre Marx e Hegel "fornece um ponto de conexão temático com a discussão internacional". Por fim, se Backhaus (1997, p.30) considerava que, em sua interpretação da teoria

3 Neste texto, usamos a expressão nova leitura de Marx - ao que tudo indica consagrada por Backhaus (1997, p.9) - para designar essa vertente em particular. Em sentido lato, contudo, ela teria uma referência mais plural e excederia as fronteiras da Alemanha. Sobre isso, ver Elbe (2010). Os projetos de Backhaus e Reichelt assumem (não sem críticas) a perspectiva da teoria crítica de Horkheimer e sobretudo de Adorno - ver Backhaus (2006); Reichelt (2013b, 1982); Bonefeld (2014); Bellofiore, Redolfi Riva (2015). Reichelt (2013b, p.11) relata que o nascimento da nova leitura se dá em 1963, quando Backhaus se depara com uma cópia da primeira edição d'O capital - então rara - na biblioteca da moradia estudantil Walter-Kolb. Mas esse achado, diz ele, só poderia produzir algum estalo em "alguém que tivesse frequentado as aulas de Adorno sobre a teoria social dialética".

4 Backhaus e Reichelt privilegiavam textos como os Grundrisse, redigidos no período de 1857-58, e o chamado Urtext, escrito em 1858, à luz dos quais teria havido uma popularização crescente do método por parte de Marx. No universo dessas elaborações, o conceito de capital em geral, predominante, era tido por eles como chave para a compreensão do projeto marxiano da crítica da economia política como um todo. Segundo Heinrich (1999, pp.179-195), entretanto, Marx teria feito uma modificação arquitetônica, com consequências teóricas, no plano daquele projeto. Para ele, no primeiro plano, que vai de 1857 até 1863, Marx ainda trabalharia com a distinção entre capital em geral e concorrência. Mas, depois disso, no segundo plano, que concerne à estrutura do que viria a ser 0 capital, Marx teria substituído aquele par pelas categorias de capital individual e capital social total. Heinrich, por isso, coloca os materiais depois de 1863 no centro de sua interpretação. É bem verdade que, diante da variedade de textos sobre a teoria do valor e das suas distintas interpretações mencionadas, Fausto (MLP I, p.125, nota 7, grifo nosso) adotou uma abordagem mais conciliatória: "se trabalharmos sobre o conjunto desses textos, é possível resolver a maioria dos problemas que eles levantaram". Para a nossa hipótese, todavia, o essencial é o diagnóstico do caráter problemático do estado da teoria. Essa pequena amostra das abordagens indica a diversidade tanto de sentidos como de textos selecionados em cada caso para a compreensão da teoria de Marx e da dialética. Apesar disso, e sem dúvida com margem de variação, todos esses esforços nos parecem compartilhar uma orientação programática e certo diagnóstico geral da teoria. 
de Marx, “interessava sobretudo o problema da 'contradição dialética'”, e se esse era um dos interesses principais de Fausto, tendo ele plena consciência (embora registrada apenas no primeiro volume de sua trilogia) de que esse debate transcorria na Alemanha, então não nos parece fora de propósito sublinhar que houvesse um alinhamento programático a ser perseguido e um diagnóstico de que a teoria dialética parecia problemática. ${ }^{5}$

Se destacamos no que se segue mais as proximidades do que as distâncias, não é para afirmar que Fausto fosse um seguidor dos autores considerados, mas, pelo contrário, para mostrar que seu pensamento estava à altura do que havia então de mais avançado na discussão. As diferenças, que incluem não só, mas também a amplitude política que ele ligava a seu projeto lógico, sem dúvida o singularizam com relação aos nomes aqui representados. Mas pormenorizar todas as diferenças, fazendo aliás justiça às preocupações políticas de Fausto - sempre o seu horizonte último - requereria um trabalho muito mais amplo. Esta contribuição pretende ser o início de uma reflexão ainda por fazer, e não sua conclusão. ${ }^{6}$

Dessa perspectiva, para compreender o quadro geral em que o pensamento de Fausto se inscrevia, convém esclarecer o que estava implicado na noção de reconstrução específica a esse contexto, marcado em grande medida pelas contribuições da nova leitura frankfurtiana. Na introdução ao volume que compila seus principais ensaios, Backhaus (1997, p.33) assume que durante algum tempo se tratou, na origem da nova leitura, da “'reconstrução' do 'método"” da crítica da economia política. ${ }^{7}$ Tal já era o leitmotiv em "Sobre a dialética da forma-valor", primeiro ensaio publicado por ele, em 1969, em que declarava que permanecia "um desiderato urgente da pesquisa sobre Marx reconstruir o todo da teoria do valor a

50 fato de que Fausto tenha conduzido seu trabalho com referência direta ao debate francês poderia suscitar uma objeção à nossa sugestão de um alinhamento programático. Sobre isso, e à guisa de primeira aproximação do problema, pode-se dizer duas coisas. Em primeiro lugar, a recepção do debate marxista francês, tão marcante em Fausto (e também em José Arthur Giannotti, em sua crítica de Althusser), não estava completamente ausente no contexto alemão. Alfred Schmidt, espécie de elo mediador entre os fundadores da teoria crítica e a nova leitura frankfurtiana, traduzia na ocasião vários textos que punham os alemães a par das controvérsias francesas durante os anos 1960. Com efeito, Schmidt (1969) publica uma crítica ao "Ataque estruturalista à história" no mesmo volume em que aparece pela primeira vez o ensaio de Backhaus sobre a forma-valor. Em 1974, o editorial do primeiro número da Gesellschaft já mostrava um engajamento com contribuições do círculo althusseriano na linha da crítica feita por Schmidt. Backhaus (1997, p.133ss) discutiria explicitamente teses de Althusser, Rancière, etc. a partir de 1978. É certo que a centralidade que a discussão francesa tem em Fausto é maior do que nos autores alemães aqui considerados. Mas se pode notar ainda que esse engajamento crítico com o althusserianismo serviu então como material comum em que se afiava o pensamento dialético tanto na obra de Fausto como nas contribuições da nova leitura frankfurtiana - conexão ex negativo cujo exame teria seu interesse histórico. Além disso, e em segundo lugar (com respeito à objeção possível), parece-nos razoável admitir que certas ideias possam ser próximas sem serem idênticas em todos os seus elementos.

6 Daí nossa opção pela apresentação de aspectos, e não por uma exposição sistemática.

7 A partir de 1978, Backhaus (1997, p.33, 132) passa a sustentar que a teoria do valor de Marx tem de passar por uma "reconstrução crítica". 
partir das apresentações mais ou menos fragmentárias e das numerosas observações singulares, espalhadas em outras obras” (Backhaus, 1997, p.42). Mas qual é então o sentido teórico geral da noção de reconstrução? O próprio Fausto aponta dois de seus pressupostos, referindo-se à teoria dialética como um todo (diagnóstico geral): “1) que a ideia da dialética como teoria rigorosa esteja, de certo modo, destruída; 2) que seja preciso e, em princípio, que seja possível reconstruí-la” (MLP I, p.15). Se essa é a concepção de reconstrução em questão, o que está destruído - ou pelo menos ainda não adequadamente construído - na teoria do valor de Marx, segundo a nova leitura, é o nexo entre valor e dinheiro, que encerra, por seu turno, o vínculo entre trabalho e valor de troca. Esse problema não diz respeito a um pormenor marxológico, mas afeta o próprio conceito de capital. Se se supõe, como deve ser o caso, que o capitalismo tenha algo que ver com o capital, então aquele não é um problema lateral para uma teoria crítica do capitalismo. Assim, ao se enfatizar a necessidade do nexo entre valor e dinheiro, no limite, entre trabalho e forma monetária, a teoria do valor só pode ser fundamentada como teoria do dinheiro. Nessa articulação se expressa a posição mais paradigmática da nova leitura, a saber, a interpretação da teoria do valor de Marx como teoria monetária do valor. ${ }^{8}$

Para entendermos as implicações, ainda que em traços muito gerais, de uma teoria monetária do valor, é preciso ter em mente que, na tradição do pensamento econômico, dinheiro e valor geralmente pertenciam a campos de investigação distintos. Assim, um autor que tenha elaborado uma teoria do valor (digamos, David Ricardo) pode não dispor de uma teoria do dinheiro, chegando mesmo a considerá-lo como um mero instrumento convencional para a facilitação da troca de mercadorias segundo o seu valor, este sim tido como objeto propriamente econômico. Ou pode haver autores que se ocupam apenas de equações relativas de valor, o qual então sai de cena para os bastidores da reflexão teórica. Aparentemente, quando se apanha um, o outro escapa. Essa separação gera dificuldades intransponíveis no pensamento econômico, das quais o jovem Marx já era, aliás, bem consciente. Nos assim chamados Manuscritos econômico-filosóficos, ele considera já em 1844 que a economia política moderna (Smith, Ricardo, etc.) eleva “o trabalho a único princípio" (MEGAI/2, p.93); isso equivalia à ideia, lê-se ainda em seu manuscrito sobre James Mill, do mesmo ano, de que a economia moderna se ocupava apenas da essência e da universalidade abstrata, ao passo que os teóricos do sistema monetário, fiando-se por completo nas equações dos preços relativos, estão presos à empiria de particularidades sem conceito. De um lado, pura essência racional, ciência dogmática; de outro, existência empírica bruta. Não é por outra razão que Marx caracteriza então a primeira corrente

8 Com a ideia já presente desde os primeiros escritos, é no segundo ensaio dos Materialien (1975), porém, que a expressão começa a tomar corpo, de sorte que Backhaus $(1997$, p.94) se refere à "teoria do valor de Marx como crítica das teorias pré-monetárias do valor". 
como "superstição refinada", enquanto a segunda é denominada "crua superstição" (MEW 40, pp.447-8) - em todo caso, superstições. Com um abismo entre essência e fenômeno, a antinomia não é transposta, mas positivada em várias escolas e correntes de pensamento.

Aesse respeito, Backhaus (1997, p.413) observa que Marx não esteve interessado em simplesmente tomar partido por um dos lados dessa antinomia - como se ele fosse um economista clássico, e não seu crítico $^{9}-$, e sim na explicação da unidade entre esses dois lados, então unilateralmente fixados. Com efeito, no mesmo sentido das reflexões juvenis, mas agora n'O capital, encontramos a célebre passagem:

É verdade que a economia política analisou, mesmo que incompletamente, o valor e a grandeza de valor e revelou o conteúdo que se esconde nessas formas. Mas ela jamais sequer colocou a seguinte questão: por que esse conteúdo assume aquela forma, e por que, portanto, o trabalho se representa no valor [...] do produto do trabalho? (Marx, 2013, pp.154-55ss.).

Dessa maneira, dizer que a teoria do valor de Marx é simultaneamente uma teoria monetária supõe que ela esteja em condições de resolver a antinomia, o que significa ser capaz de expor o nexo necessário entre o valor-trabalho como conteúdo (essência, obtida na análise da mercadoria) e o dinheiro como sua forma necessária de existência (aparecimento, necessidade deduzida na análise das formas do valor). Sob essa perspectiva, afirma Backhaus (1997, p.73): "Parece-me que a concepção corrente, que trata as teorias do valor e do dinheiro de Marx como partes teóricas diferentes por princípio, não apreende a essência da análise da forma-valor". ${ }^{10}$

Tudo somado, para a nova leitura, a teoria (monetária) do valor de Marx exige que o valor não possa ter uma existência pura independentemente do dinheiro, isto é, ela rejeita a possibilidade de existência de uma substância puramente racional que não se apresente, simultaneamente, em forma fenomênica. "A essência tem de aparecer" (Hegel, 2017, p.133). Seguindo essa tradição, “Marx se orienta bem mais pela filosofia hegeliana ao compreender a essência não como absolutamente transcendente", lembra Reichelt (2013a, pp.95-6), "mas como essência que tem de aparecer - como na concepção hegeliana -, mais exatamente, tem de aparecer plenamente; se não aparecesse, não seria a essência". ${ }^{11}$ Ou nas palavras do professor

9 Sobre Marx como crítico da economia política clássica, ver Grespan (2001).

10 Backhaus (1997, p.73) chega a condicionar a validade da teoria do valor de Marx à validade da sua teoria monetária.

11 Nessa passagem, Reichelt se referia ao conceito geral de capital. A sequência diz: "Nesse caso, as categorias só são 'formas de manifestação de relações essenciais' porque o capital universal 'aparece' para o capitalista, para o 'capital existente para si', mas aparece - e esse é justamente o ponto de vista decisivo - ao mesmo tempo em que se oculta no ato de aparecer. É isso que gera problemas para a ciência, pois esta só se constitui em virtude dessa diferença entre essência e fenômeno" (Reichelt, 2013a, pp.95-6). Também o dinheiro expõe o valor como existente, nessa exposição, contudo, e a um só tempo, pressupondo e ocultando o valor como sua essência. 
de Reichelt contra a ontologia: “Nenhum ser sem ente” (Adorno, 2009, p.199). Fausto (1997, pp.31-2) também é consciente da necessidade do aparecimento para o conceito de essência: "há um momento de ilusão da essência, em que ela 'esquece' que é da essência da essência aparecer". De acordo com Backhaus (1997, p.43), não só as interpretações costumeiras do marxismo, mas o próprio Marx não teria sido bem sucedido precisamente na dedução desse vínculo dialético: “A mediação insuficiente de substância e forma do valor já está expressa no fato de que uma ruptura pode ser vista no desenvolvimento do valor", afirma ele, referindo-se à "passagem da segunda para a terceira seção do primeiro capítulo", que, na forma como Marx a deduziu, “já não é compreensível como passagem necessária”. Se isso é verdade, a "análise da mercadoria realizada por Marx se apresenta então como um 'salto' - não mediado - 'do simples para o complexo, da substância para a forma de aparecimento" "12 (idem, p.44). O resultado é que a "mediação entre essência e forma de aparecimento só pode ser construída como um movimento pseudodialético de contradições pseudodialéticas" (idem, ibidem). ${ }^{13}$

Se esse é o corolário da apresentação marxiana do valor e suas formas, e se ele é considerado falso porque assevera os nexos relevantes por meio de "contradições pseudodialéticas", então é evidente que nesse juízo é suposta uma articulação íntima entre verdade e contradição dialética: uma apresentação não contraditória, nesse caso, é índice de não verdade. Como procuraremos mostrar a seguir em alguns aspectos, o esforço de Fausto será restituir o rigor daquela articulação.

\section{A reconstituição da dialética segundo Fausto}

Muitas das questões anteriores aparecem com a mesma força na reconstituição da dialética em Fausto. Para ele (MLP I, p.122), que conduz sua reconstituição se confrontando com as críticas a Marx orientadas pela lógica da identidade, "toda crítica de $O$ Capital que não toma a sério a dialética como discurso da contradição só pode conduzir a uma regressão. É esta regressão, esta volta aquém de Marx que está em questão, não o projeto de ir além, o qual, pelo contrário, é a tarefa de todos nós". Fausto parece enveredar por um caminho que Alfred Schimdt (1974, p.43), em 1967, julgou necessário trilhar para a determinação do conceito de conhecimento na crítica marxiana da economia política: “Embora Marx não tenha escrito uma lógica ou uma teoria do conhecimento no sentido tradicional, [...] ele escreveu a

12 A citação feita por Backhaus está em Banfi, R. (1972). Probleme und Scheinprobleme bei Marx und im Marxismus. In: Mohl, E. T. et al. Folgen einer Theorie. Frankfurt a.M: Suhrkamp, p.172.

130 salto, a ser localizado principalmente nas edições subsequentes à primeira, ocorreria entre os itens 2 e 3 do primeiro capítulo, em que Marx formula o conceito de trabalho abstrato como "dispêndio de força humana em sentido fisiológico" (Marx, 2013, p.124, grifo nosso). Tal conceito, nessa formulação naturalista, apresenta o trabalho como mera generalidade no sentido do típico, do geral como elemento comum e invariável, do conceito genérico da lógica formal, que se obtém por simples abstração de singularidades dadas (Backhaus, 1997, pp.44-5). 
dialética estritamente objetiva do Capital, cuja riqueza de intuições e problemas filosoficamente relevantes está longe de se esgotar”.

Em sua reconstituição, porém, os elementos políticos da lógica dessa formação teórica consistirão em seu ponto de fuga principal. Assim, os termos "lógica" e "política” presentes no título do seu programa visam respectivamente aos “"fundamentos' lógicos da crítica da economia política” e à "prática política” (MLP I, p.14) ${ }^{14}$.

Como a nova leitura, Fausto examina a dialética em Marx retomando Hegel, cuja concepção lógica é mobilizada na compreensão da crítica marxiana da economia. Para Fausto, a Ciência da lógica constitui o universo filosófico principal de suas reflexões. ${ }^{15}$ Ali a ciência lógica chega a seu conceito como a apresentação crítica da "metafísica propriamente dita" (Hegel, 1986, p.16). Segundo Fausto, o discurso marxiano não é, certamente, o discurso hegeliano, mas a dialética que Marx desenvolve é tributária da lógica hegeliana e deve ser compreendida também no âmbito de uma lógica dialética. No centro dessa concepção, seja ela hegeliana ou marxiana, encontra-se a ideia de que é a partir da dialética como posição das antinomias do entendimento que se pode chegar ao verdadeiro conceito da coisa ou da efetividade. Conforme sua leitura, a partir da inflexão marxiana, mais do que um discurso da contradição, a dialética se tornará um discurso da interversão (Umschlag) (ver MLP I, p.55). Para chegar ao conceito de interversão, vejamos primeiro a especificidade que Fausto enxerga na relação entre o discurso metafísico e a realidade da contradição.

\section{Metafísica e o feitiço do mundo desencantado}

Hegel (1986, p.45) considera que a lógica assume o lugar da metafísica, o que ocorre em seu pensamento como uma transformação crítica da metafísica em lógica - o que ele já via prenunciado em Kant. Se em Hegel a metafísica só pode ser verdadeiramente concebida como um pensamento objetivo, que em vista da superação de sua aparente cisão com o objeto rompe a cobertura subjetiva das contradições, em Marx ela assume certamente outro propósito que sua redenção secular e persiste em certo aspecto porque a objetividade capitalista parece possuir uma consistência metafísica, sendo assim como que preservada com um sinal invertido. Para Fausto, importa reter que "Marx concebe a realidade (social) como um universo habitado

14 As preocupações teóricas de Fausto sempre se referiram à fundamentação da política, não obstante a política tenha, nos últimos escritos, de certo modo se destacado das perspectivas aqui discutidas. Para um panorama sobre o vínculo entre lógica e política em Fausto, ver Nascimento (2020). No caso da nova leitura, a política quase não aparece como tema da teoria.

15 Para Fausto, determinados desenvolvimentos teóricos da dialética marxiana não podem ser considerados sem referência à Fenomenologia do espírito. Ver, por exemplo, sua interpretação sobre a história em Marx (MLP I, pp.27-35) e o caso da mistura - espécie de "brouillage" - entre forma e conteúdo característica da seção VII do livro III d’O capital (Fausto, 1993, p.47-48). 
por 'coisas' e 'forças'”' (MLP I, p.101). Ao contrário da crítica hegeliana às categorias do entendimento, a crítica marxiana das categorias da economia política, embora incompleta, não pretende reconciliar coisa e pensamento na realidade capitalista; ela mostra não apenas o seu caráter contraditório, mas invertido, transitório e, no limite, revogável. ${ }^{16} \mathrm{~A}$ análise da forma-valor, tal como interpretada por Fausto, quer decifrar aquela consistência metafísica. Ele enfatiza que a "dialética da forma do valor não é gênese do valor de troca, mas gênese do dinheiro [...]. Ao contrário do que ocorre para o dinheiro, o valor de troca está presente enquanto valor de troca desde o início, embora não de uma forma adequada" (MLP I, p.165). Com isso, o dinheiro aparece como forma adequada da expressão do valor: "Tal é o sentido da 'realidade efetiva' da expressão do valor, ou de sua presença 'verdadeira'” (idem, ibidem). Dito de outro modo, o valor, essência puramente social, na qual não se acha nenhum átomo de matéria, põe-se materialmente como dinheiro, coisa sensível. Rigorosamente, o dinheiro é a existência do valor no mundo sensível. Assim, a crítica precisa acolher o caráter da abstração, que, não suprimida, perpassa de fato a forma social existente analisada por Marx, de modo que, nesta forma mesma, contradictio est regula veri, non falsi. ${ }^{17}$

Graças ao caráter contraditório, de base aparentemente metafísica e, ainda assim, real da objetividade fantasmagórica do valor, e dada ainda a dificuldade de Marx em apresentá-las de maneira adequada, supôs-se que sua apresentação transcorria como uma mera "tautologia metafísica", como acusa Cornelius Castoriadis, que, como tantos outros, qualificou o primeiro capítulo d'O capital como "metafísico" (MLP I, p.100). Para Fausto, o próprio Marx teria reconhecido "que o seu discurso tem algo de metafísico. Mas a metafísica do seu discurso é a reprodução da metafísica do real" (idem, ibidem). Em conformidade com isso, "[é] o real, o capitalismo que é em certo sentido metafísico, e o discurso quase metafísico é por isso o verdadeiro discurso científico, assim como o discurso claro da 'ciência' se torna nesse caso inadequado" (idem, ibidem).

0 caso da mercadoria é exemplar por se tratar de um "objeto sensívelsuprassensível". A compreensão desse "tipo muito particular de objeto" dependeria de "um discurso que se ajuste a ele, isto é, um discurso que ponha essas abstrações objetivas como elas são efetivamente: como coisas sociais que reduzem os agentes a

16 Portanto, não haveria em Marx uma espécie de "metafísica da economia política" (MLP I, p.100). Já no seu primeiro livro, Reichelt (2013a, p. 90) sustentou que a dialética idealista seria a "duplicação filosófica da inversão real", ao passo que a dialética materialista seria o "método a ser revogado, que desaparecerá junto com as condições de sua existência". Ele segue aqui uma concepção autorreflexiva e autocrítica que Adorno (2003, p.139) atribui à teoria dialética: "A teoria é pressuposta e empregada aqui para aboli-la em sua figura corrente. 0 ideal de uma figura modificada seria sua prescrição".

17 Não é apenas n'O capital, portanto no discurso de maturidade, que Marx (2013, p.146), ao analisar a mercadoria, decifra nela um "sensível-suprassensível". Já nos Manuscritos, ele caracterizava o "dinheiro como conceito existente e atuante do valor" (MEGA I/2, p.321, grifo nosso). 
suportes" (MLP I, p.101). Por isso, acusar Marx de metafísico seria uma ingenuidade. 0 central em seu argumento é compreender por que a realidade se apresenta como dotada de consistência quasi-metafísica, e não a representar como se por detrás de algum véu ou distorção se achasse um modo racional de reprodução da sociedade.

Mais do que inadequado a essa realidade, o pensamento claro do entendimento que tentasse apreendê-la desse modo se interverteria em mistificação. A concepção peculiar, quase escandalosa, do metafísico em Marx se deixa exemplificar na comparação que Fausto (1997, p.151) realiza entre a modernidade de Marx e a de Max Weber. Neste último, haveria “uma espécie de convergência entre as exigências metodológicas e as teses substantivas, no sentido da eliminação de toda 'fantasmagoria'”, sendo então "preciso clarificar absolutamente os conceitos, o que significa subjetivar", isto é, pôr os agentes, "pois só os agentes são objetivos". De acordo com essa orientação metodológica, a "tese substantiva: o capitalismo é o mundo desencantado, mundo em que desapareceram as representações 'mágicas'”, o qual faz que forma e conteúdo pressionem o pensamento no sentido "rigorosamente aufklärer". Contudo, prossegue Fausto na mesma passagem, o "problema é que há no capitalismo alguma coisa como um mundo encantado", e que precisamente esse mundo é, em parte, "um mundo objetivo". ${ }^{18}$ Assim, ao "desencantar um mundo objetivamente encantado, o aufklärer Weber é vítima da dialética da Aufklärung (tal como Marx já a conhecia)”. Tal discurso “corre o risco de 'encantar', isto é, de mistificar, porque clarifica o que não é objetivamente claro" (idem, ibidem). ${ }^{19}$

De maneira análoga, Backhaus (2021, p.145) afirmaria mais tarde que a renúncia da economia "à elaboração de um conceito social de valor, ou seja, à análise de abstrações objetivamente reais", torna-a sujeita "à suspeita de que sua formação conceitual estaria fundada, de modo geral, em afirmações existenciais monstruosas, na formação de pseudoconceitos situados no 'campo do pré-social'”. Numa análise imanente das teorias econômicas de Schumpeter, Wicksell, Jevons, entre outros, ele mostra como as tentativas analíticas e empiricamente orientadas, ao liquidar o elemento qualitativo, quasi-metafísico e objetivo que o nexo social possui na sociedade capitalista, são obrigadas a assumir, sem dedução, a existência de entidades absurdas. O discurso claro do entendimento se interverte em uma ingênua metafísica positiva. Os “conceitos como 'matéria econômica' e 'energia econômica"”, continua Backhaus (idem, ibidem), "serviriam como 'pressupostos tácitos’ daquela disciplina":

18 Em suma, o universo do "fetichismo é, de certo modo, o mundo encantado no interior do mundo desencantado" (MLP II, p.55).

19 Por outro lado, ainda no interior da dialética, o entendimento também limita a razão. Para Fausto, a dialética marxiana é uma dialética limitada (ver Fausto, 1993; MLP II, pp.169-74). Há um "equilíbrio instável" entre entendimento e razão, "é como se cada um invadisse a esfera do outro" (Fausto, 1993, p.55). É nesse sentido que, em sua leitura, a dialética marxiana é simultaneamente crítica dialética ao entendimento e crítica do entendimento à dialética (ver MLP II, p.173). 
Trata-se nitidamente de exemplos paradigmáticos da tese de Adorno de uma "interversão" necessária de conceitos quantitativos, aparentemente "exatos", em "especulação selvagem" e "monstruosidades". De fato, a aparência objetiva dessa quasi-matéria - a "objetividade fantasmagórica" ou "objetividade de valor" de que fala Marx - é tão densa, que alguns economistas sucumbiram à tentação cientificista de querer extrair, no sentido da "analogia mecânica", "aspectos da física atômica em vista da determinação do conceito de capital”.

$\mathrm{Na}$ interversão do discurso, patenteia-se ainda Adorno como referência comum entre Backhaus e Fausto, embora mais conscientemente para o primeiro e só paulatinamente para o segundo. ${ }^{20}$ Assim, Backhaus (1997, p.299) se referia à crítica adorniana ao "postulado da clareza". A sociedade é tal que "ela porta traços incompatíveis com sua pretensão interna de racionalidade", cabendo à teoria o esforço de "pensar claramente o que não é claro", não convertendo de modo algum, todavia, esse modo de pensar em "critério da coisa mesma" (Adorno, 1993, p.63). Se não é apenas o "caráter contraditório" que pertence à “legalidade objetiva da sociedade", mas também sua "irracionalidade", então a teoria dialética da sociedade se deve incumbir, lembra Backhaus citando Adorno (1993, p.53), da tarefa de "refleti-la e possivelmente deduzi-la", ao invés de afastar a irracionalidade de maneira analítica. É precisamente a dedução da irracionalidade que Marx (MEW 26.3, p.509) teria em mente ao insistir em que uma "irracionalidade da coisa mesma" define a estrutura essencial da economia, de modo que esta seria "deturpada" tão logo o economista procurasse “torná-la racional”.

\section{Da antinomia à contradição}

Uma vez estabelecida essa especificidade do discurso marxiano para Fausto, consideremos agora outro aspecto: a contradição como posição dialética das antinomias na crítica da economia política. Como sentenciaria Fausto (2015, p.14) no texto de apresentação da mais recente edição do seu primeiro tomo, rebatizado Sentido da dialética: "o ponto de partida da dialética é sempre uma antinomia".

Ele argumenta que a dialética funcionaria, entre outras determinações, segundo a relação de posição e pressuposição, que articula as componentes da crítica marxiana - economia, política, ideologia, antropologia, etc. Esse par conceitual, tão importante para Fausto, costura logicamente diversas passagens categoriais. A dialética transitaria entre os discursos implícito e explícito, entre suas intenções

20 "Na realidade", escreve Fausto (MLP III, p.74, nota 13) sobre o que se preservaria do marxismo em seu pensamento, "o modelo dialético que me serve de referência é - junto com a dialética de Adorno, que tem relações complexas com o marxismo - mais o da dialética de Marx do que o da dialética hegeliana". Ou antes, em 1993: "Apesar das aparências em contrário, o meu tema do papel do entendimento se reconcilia com o tema de extração frankfurtiana da dialética negativa" (Fausto, 1993, p.58). Evidentemente isso não implica que haja apenas continuidade entre todos esses autores. 
não satisfeitas e sua efetividade. O que Fausto qualifica como o "descobrimento de Marx" é justamente a posição do conteúdo não expresso pela economia política (MLP I, p.152-53), isto é, aquela passagem do implícito no explícito. Tem-se, portanto, um movimento que busca, pela posição da contradição, apreender aquilo que não se tematiza em primeiro plano, sendo uma das figuras analíticas do processo de interversão. ${ }^{21}$

Assim, em termos lógicos, os momentos de aparecimento, que incluem a dimensão do vivido, poderiam ser apreendidos, em sua generalidade, à maneira de posição do pressuposto. Isso significa que também a análise do vivido não dispensa a reflexão lógica, mas, sem ser nesta esgotada, em todo caso a requer. Seus impasses e problemas, replicados nas teorias e práticas marxistas ao longo do século XX, precisam ser examinados nas antinomias e aporias que produziram, algo que, segundo Fausto, costuma ser meramente contornado ou até mesmo ignorado por aqueles que se ocupam de Marx. ${ }^{22}$

No entanto, assim como Backhaus, Fausto observa que Marx não assume nenhum dos polos das antinomias, especialmente aquelas da economia política. Vejamos, então, como Fausto reconstitui, na forma da contradição, o caso da antinomia de valor e preço. Esta corresponderá, logicamente, à antinomia de essência e aparecimento. De acordo com ele, a "maneira pela qual Marx vai resolver esta antinomia corresponde, no plano da crítica da economia política, à solução dada por Hegel às antinomias da tradição filosófica” (MLP I, p.119).

Se temos, por um lado, Adam Smith e principalmente David Ricardo, que frequentemente procuraram conservar a lei do valor (essência) sem explicar a forma de aparecimento do valor (preço; fenômeno), por outro lado, encontram-se autores como Thomas Malthus, Samuel Bailey, etc., que, em sua crítica à escola ricardiana, procuraram calcular a formação dos preços em detrimento da sua essência. Em contraste a essas duas posições, Marx procura analisar a relação entre a essência e o fenômeno conservando ambos em sua análise da contradição entre valor e preço. Seria esta posição de Marx, que se "instala na contradição", que "constitui $a$ originalidade de sua resposta diante da economia política” (MLP I, p.20).

21 Por questões de espaço, não é possível apresentar todo o alcance e sentido do par pressuposição e posição no interior da reconstituição de Fausto. Uma apresentação robusta deste par teria que satisfazer ao menos três condições de análise: 1) determiná-lo ali onde é tematizado por Hegel, a saber: na lógica da reflexão da Doutrina da essência da Ciência da lógica; 2) compreender o seu funcionamento na dialética marxiana; 3) determinar a maneira pela qual Fausto entende esse par e suas modalidades no interior da sua reconstituição. Em função do enfoque dado aqui ao processo de interversão, que abarca os pares mobilizados por Fausto (pré-história e história, humanismo e anti-humanismo, etc.), o par pressuposição e posição está ele mesmo como que pressuposto no exame dos aspectos de seu projeto reconstrutivo.

22 Cabe lembrar que Fausto se propõe a analisar e criticar o marxismo. A crítica das críticas a Marx não gostaria de "salvar o marxismo, mas tornar possível uma verdadeira superação dele: evitar que se abandone grandes textos sem crítica pertinente" (Fausto, 1983b, p.3). 
Seguindo tal argumentação, Fausto registra os momentos em que são apontadas as insuficiências teóricas de Smith e Ricardo. Assim, Smith não teria percebido a contradição que se instaura entre sua teoria do valor-trabalho e a afirmação de que a massa de lucro dependeria da grandeza do capital investido. Ricardo, por sua vez, teria sido o primeiro a encostar na contradição ao identificar que capitais de mesma grandeza não possuem a mesma composição orgânica. Mas, segundo Marx, ainda assim Ricardo não teria conseguido exprimir a contradição entre diferentes composições orgânicas de capital e a lei do valor. "Pelo contrário, ele se põe a pesquisar o valor com a pressuposição do capital e de uma taxa de lucro geral. Identifica desde o início preços de custo (Kostenpreise) e valores e não vê que desde o início esta suposição contradiz prima facie a lei do valor” (MEW 26.3, p.45). ${ }^{23}$ Este é um lado da antinomia que se coloca para a economia, visto que Smith e Ricardo reteriam apenas e limitadamente a lei do valor como essência racional. No fundo, e aqui antecipamos o passo de Marx, essa explicação não seria suficiente, pois é necessário determinar por que o trabalho, conteúdo do valor, é levado a assumir aquela forma de aparecimento (preço), que no entanto contradiz a lei daquele conteúdo. Em uma palavra, com a antinomia entre valor e preço, não se trata só de uma antinomia entre conteúdo e forma, mas também entre lei e experiência, necessidade e contingência.

Haveria então, por outro lado, uma direção oposta àquela, "pela qual enveredou também a economia política”, "a daqueles que indicam a contradição mas querem expulsá-la - e isto admitindo o fenômeno e negando o fundamento" (MLP I, p.118). Esta será a posição da economia vulgar, tal como batizada por Marx e que ele exemplifica nos trabalhos de Malthus e outros. Segundo Fausto (idem, ibidem), "podese opor estes últimos aos clássicos”, Smith e Ricardo, ou “dizendo que eles negam, abstratamente, a contradição, enquanto que os clássicos a admitem, abstratamente também, isto é, eles a sofrem sem tomar consciência dela"; ou dizendo "que eles guardam o fenômeno e sacrificam a essência, enquanto os clássicos, num sentido pelo menos, guardam a essência sacrificando o fenômeno". Portanto, ele prossegue, a fim de "expulsar a contradição entre o fenômeno (a igualdade dos lucros para capitais da mesma grandeza) quaisquer que sejam a composição e a essência (valor) que deveriam fundá-lo, eles renunciam à teoria do valor e a toda fundação” (idem, ibidem).

Fausto procura mostrar como Marx põe a contradição da antinomia de valor e preço, pondo com isso a mediação de essência e fenômeno, cuja relação implicará não uma solução positiva, um novo princípio ou um novo paradigma da ciência econômica, mas a exposição de uma contradição objetiva que põe a descoberto a realidade efetiva capitalista. 0 tratamento deste problema, diz Fausto, acha-se nas considerações de Marx sobre o conceito de preço de produção:

23 Tradução de Fausto (MLP I, p.118). 
[S]e a solução do problema reside, como se sabe, no conceito de preço de produção - as mercadorias são vendidas não segundo os seus valores $(c+v+p l)$, mas segundo os seus preços de produção $(c+v)$ (= preço de custo $)+$ lucro médio, estabelecendo uma partilha do conjunto da mais-valia segundo a grandeza dos capitais, é preciso acentuar o que existe de escandaloso nesta resposta, exatamente aquilo de que Engels procurava fugir. (MLP I, p.120) ${ }^{24}$

Daí que, para Fausto, "se o fenômeno é um nível do real, e é necessário considerá-lo assim, a lei do valor só é conservada ao preço da negação. O valor é negado no nível do fenômeno" (idem, ibidem). A resolução de Marx não consiste em desatar idealmente a contradição em uma apresentação em que ela mesma desse lugar à restituição de uma identidade livre de contradição, escapando assim à antinomia de princípio (clássicos) e ausência de princípio (vulgares) na forma do ou-ou. A contradição como critério de verdade da teoria, a vida conjunta de ciência e contradição, implica a possibilidade de apreender o mecanismo que sempre repõe a antinomia. 0 impasse que se configura na citação de Fausto pode ser esclarecido, em termos lógicos, da seguinte maneira: a lei do valor, inscrita no plano da essência, parece contradizer o fenômeno, que se apresenta no plano da existência dos preços e que, no entanto, só pode desdobrar o seu fundamento a partir da essência que parece negá-lo: se afirmo os preços, nego o valor e sua lei; se afirmo o valor, nego o fundamento dos preços. Apesar da aparência de autossubsistência com que se deixam representar, eles não são verdadeiramente autossubsistentes. Esse problema parece apenas aporético para a representação: ou a manutenção da lei de igualdade dos lucros, implicando o abandono da "base racional da economia política", ou a manutenção da lei do valor, negando-se a igualdade de lucros para capitais de mesma grandeza. ${ }^{25}$ Como lidar com essa contradição? De fato, posição da antinomia, deduzir a contradição, isto é: dialética.

Mas o sentido geral da solução proposta por Fausto para essa problemática nos força ainda a um desvio do âmbito lógico-sistemático. Esse desvio desloca o ângulo de consideração para a relação entre o lógico e o histórico e, assim, para a filosofia da história. Tentemos, pois, delinear o modo como Fausto concebe esse

$24 \mathrm{Em}$ que $\mathrm{c}=$ capital constante, $\mathrm{v}=$ capital variável e $\mathrm{pl}=$ mais-valor. Fausto se esquece de traduzir pl (plus-value) por m (mais-valor, Mehrwert). A crítica das interpretações de Engels, que, entre outras coisas, identifica o lógico e o histórico no modo de apresentação das categorias, construindo a ficção de uma produção simples de mercadorias pré-capitalista, é uma das características da nova leitura, perpassando quase todos os seus textos.

25 Esse problema, cuja reprodução mais exata nos levaria muito longe, remonta em todo caso, decerto em nível anterior da exposição, já àquele da transformação do dinheiro em capital no livro I d'O capital, a saber: como, a partir da lei do valor, admitida na análise da mercadoria e do dinheiro, chega-se à determinação do excedente de valor, diferença que parece violar aquela lei? Reichelt (2013a, p.255) formula o problema da seguinte maneira: "Ou são trocados equivalentes e, nesse caso, não pode haver mais-valor ou então há o capitalismo e não existe troca de equivalentes". No nível de apresentação específico do processo de produção, a solução passará pela determinação da força de trabalho ela mesma como mercadoria e seu "consumo". 
deslocamento e o sentido geral de sua argumentação introduzindo mais um aspecto da sua reconstituição.

\section{Lógica e história}

Intimamente ligado ao conceito de valor, o trabalho abstrato, Fausto enfatiza, não pode ser projetado para a pré-história do capitalismo. De fato, seria preciso entender o lugar determinado da lei do valor em sua história contemporânea. Mas Marx complica as coisas. Por vezes a dimensão histórica se entremeia com a apresentação lógica, e a explicação se torna intrincada. Na leitura de Fausto, o valor é, como qualquer outro ser em sua pré-história, negado, de modo que não se poderia atribuir existência pré-capitalista ao valor. ${ }^{26}$ No capitalismo, o valor se torna sujeito graças à imposição do tempo de trabalho socialmente necessário que se estabelece no nível da produção segundo a forma-mercadoria. No entanto, salienta Fausto, “existem [...], no nível da pré-história, certas determinações que exprimem mas que ao mesmo tempo não exprimem esse ser, isto é, existem certas determinações que exprimem este ser (ausente enquanto sujeito) em forma negativa, em forma contraditória" (MLP I, p.113). No caso do valor no capitalismo se passa o mesmo, dando-se sua negação na forma de aparecimento do preço: se "não se pode dizer que a lei do valor tenha chegado a existir antes do capitalismo, se deverá concluir que é só quando o valor não é mais que o valor é, ou que o valor só é quando ele não é" (MLP I, p.120). Em outras palavras: do mesmo modo como o valor é pressuposto nas formas pré-capitalistas de produção social, sendo posto como negado, isto é, na forma predicativa que diz não-valor - ou seja, as diversas relações sociais de produção pré-modernas, não capitalistas, relações de troca que não têm o valor como conteúdo e fundamento -, o valor, no modo de produção capitalista, é posto como "negado" - suspenso - na forma do preço, que, como forma necessária de aparecimento do valor, não pode de modo algum coincidir com este e antes o

26 Segundo Fausto, a pré-história é, em termos lógicos, o âmbito de afirmação do ser pelos seus predicados, ao passo que a história coincide com sua afirmação como sujeito. Isso significa que no domínio da pré-história como história dos predicados, o ser se determina a partir de um outro, o que implica sua posição negativa. No caso da dialética marxiana, diz Fausto (MLP I, p.31), importa notar que os sujeitos (o trabalhador e o capitalista), concebidos como suportes do capital (determinados, portanto, em conformidade com seus predicados), estariam em segundo plano justamente porque a teoria em questão tematiza o "sujeito" capital, do que se segue sua posição como universal concreto e a redução dos sujeitos a meros agentes de suas funções. Daí a posição de Marx que afirma, com a supressão da formação social capitalista, o fim da pré-história da sociedade humana. Essa questão também se vincula, portanto, às controvérsias em torno do humanismo. Tirando as consequências desse estado de coisas, Fausto desenvolve a ideia de que "toda posição do homem implica uma interversão no seu contrário; isto é, o humanismo - o humanismo se caracterizando pela posição do homem - é na realidade um anti-humanismo (o humanismo se interverte em anti-humanismo), e que só a 'supressão' (Aufhebung) do humanismo permite escapar ao 'juízo' (inclusive em sentido 'jurídico') 'o humanismo é um anti-humanismo' e permite assim 'suprimir' tanto o humanismo como o anti-humanismo”. (MLP I, p.32). Tópico que não podemos aprofundar aqui. 
esconde em seu aparecer. Como afirma Marx (2013, p.167), o "movimento mediador desaparece em seu próprio resultado e não deixa qualquer rastro". A esse respeito, Fausto conclui o seguinte:

O aparecer da essência parece não ser a essência. Mas esse parecer é essencial ao aparecer. 0 aparecer da essência consiste em parecer ser outra coisa do que a essência, e ao mesmo tempo só em parecer ser mas na realidade não ser outra coisa. Os dois lados devem ser fixados ao mesmo tempo. A aparência só é verdadeira quando ela é expressa como sendo a aparência da essência. Ela só é verdadeira quando não é ela mesma, mas a identidade dela com ela mesma, se se quiser o seu momento de inverdade, faz parte da sua verdade. A sua verdade consiste em ser verdade de um outro e em um outro, mas ela só é verdade em um outro se parecer ser verdade em si mesma. (MLP II, pp.86-7)

Todavia, cumpriria examinar se a transitividade entre os níveis do lógicosistemático e do histórico admite tal solução de continuidade proposta por Fausto, ainda que muito mais complexa do que a identidade lógico-histórica proposta por Engels.

\section{Interversão e liberdade}

Se a objetividade da contradição pode ser confirmada na posição da relação de preço e valor, de saída uma relação antinômica na ciência econômica - confirmandose ainda a contradição como um discurso da verdade -, ela compreende também um processo de interversão, que exprime o fundamento do capital e, abrindo o horizonte da prática, permite tematizar a liberdade.

No parágrafo 1 do capítulo 21 do livro I, parágrafo cujo título "Interversão das leis de apropriação da produção de mercadorias em leis da apropriação capitalista”, já diz muito sobre o método de Marx, ele escreve a propósito do problema da passagem da circulação simples de mercadorias à produção capitalista: “Dizer que a interposição do trabalho assalariado falseia (fälscht) a produção de mercadorias quer dizer que, se a produção de mercadorias quiser se manter não falseada (unfälscht), ela não pode se desenvolver". Texto que é preciso ler, de acordo com o conjunto do capítulo que descreve uma interversão (Umschlag), sem atenuar o seu sentido: é só quando as leis da produção das mercadorias são "falseadas" (isto é, são negadas) que elas são plenamente. (MLP I, p.120, grifo nosso)

Com isso se introduz o processo de interversão que Fausto registra como o movimento mais importante que a dialética marxiana transmitiu. Tal processo ganha certa preponderância na leitura de Fausto e deve ser aqui considerado novamente, mas agora, em suas linhas gerais, também no âmbito da prática vivida. Sua reconstituição é, como não podemos nos esquecer, um programa que consiste em relacionar dois aspectos aparentemente sem relação: o lógico e o político. A interversão representa um transbordamento, por assim dizer, do próprio discurso de Marx. Para Fausto (1983b, p.4), com ela é possível ir além de Marx (e, acrescentaríamos, também da 
nova leitura):

[O] movimento de interversão recoloca de certo modo o nível da experiência vivida. Por outro lado, e as duas coisas convergem, o interesse da interversão está em que ela representa um movimento crítico que pode ser "exportado" para terrenos diferentes daquele em que se exerce em geral a crítica em "O Capital".

Essa “exportação” alude às pretensões da reconstrução faustiana, as quais, ultrapassando o âmbito da crítica da economia política e seu núcleo, a teoria do valor, miram a dialética como um todo, que passa a tematizar o momento não lógico da lógica. Como anunciamos, consideremos brevemente outro processo de interversão, agora voltado à filosofia prática: a interversão da noção de liberdade. Fausto parte das afirmações de Marx sobre o duplo sentido da liberdade no capitalismo, encontradas nos Grundrisse e n'O capital. Conforme consta nos Grundrisse, o contingente de pessoas expulsas do campo, "uma massa de força de trabalho viva”, é "livre em duplo sentido": de um lado, "livre das antigas relações de clientela ou dependência e das relações de serviço"; de outro, "livre de qualquer bem, livre de toda forma de existência objetiva material, livre de toda propriedade, dependendo da venda da sua força de trabalho, ou da mendicância, da vagabundagem e do roubo, como única fonte de rendimento" (Marx, 1953, p.406). ${ }^{27} \mathrm{E}$, n’O capital: o trabalhador é livre "em dois sentidos: de ser uma pessoa livre, que dispõe de sua força de trabalho como sua mercadoria, e de, por outro lado, ser alguém que não tem outra mercadoria para vender, livre e solto, carecendo absolutamente de todas as coisas necessárias à realização de sua força de trabalho” (Marx, 2013, p.244). A bem dizer, o trabalhador é o único possuidor de sua força de trabalho, que ele deve vender para realizá-la, pois não pode fazer pelos seus próprios meios - liberdade que se realiza em um processo de submissão. Segundo a leitura de Fausto, aqui apenas aludida, ao empregar "liberdade" de modo positivo e negativo, Marx cairia "efetivamente numa contradição: o sujeito 'liberdade' é contradito pelo predicado 'a separação entre o trabalhador e os meios de produção', que nada tem a ver com a verdadeira liberdade” (MLP I, p.52). Todavia, na interversão de "liberdade” em "não liberdade”, não está em causa a abolição ou efetivação do ideal de liberdade; antes, a contradição posta pela interversão deve servir como ponto de fuga metalógico para a prática, em direção à abolição da contradição objetiva que repõe aquele conceito antinômico de liberdade. De acordo com Fausto, Marx mantém a interversão e lhe dá "um conteúdo (um predicado) que contradiz a ideia de liberdade", e ao fazer isso, ele reproduz, "no nível da expressão a contradição real da liberdade burguesa" (idem, ibidem). No discurso marxiano sobre a produção social capitalista, a liberdade é posta como negada. A interversão da liberdade capta e evidencia a contradição entre a 27 Tradução de Fausto (MLP I, p.51). 
pressuposição da liberdade como norma das relações de troca e sua posição como não liberdade. Em suma, a liberdade ainda não é. Com o movimento de interversão da liberdade, considerada pela economia política e pelos "socialistas beletristas" (Marx, 2011, p.48) como simples princípio a ser realizado, apresenta-se sua nota promissória: a norma da liberdade que vigora na circulação simples aparece como não liberdade nesta circulação como circulação do capital. Fausto retém o sentido crítico do movimento, que mostra que a figura na qual o pressuposto é exposto conserva como suspensa a validade daquele princípio. No limite, a validade da liberdade como norma implica sua negação na realidade.

Em sua crítica a José Arthur Giannotti, especificamente ao Origens da dialética do trabalho, pode-se precisar a intenção de sustentar negativamente a contradição. Fausto (MLP I, p.245, nota 3) enfatiza que o trabalho de Giannotti possui o mérito de adotar como “noção central a diferença entre pressuposição e posição". No entanto, continua, a análise de Giannotti reduziria "o alcance da crítica de Marx à economia política" - por não ultrapassar a relação de troca, tendo antes centrado sua reflexão no momento da igualdade na equivalência - "e, do ponto de vista lógico, ficase finalmente aquém da contradição" (idem, ibidem). O que se teria perdido de vista com isso é o momento da reprodução, isto é, o momento da desigualdade na equivalência. Assim, embora a relação entre posição e pressuposição esteja presente em Giannotti, a contradição, segundo Fausto, “não é realmente apresentada de forma rigorosa", o que, a seu ver, reduz o alcance da crítica marxiana, e sobretudo o aspecto político da vinculação lógica é perdido. ${ }^{28}$ Com isso, Fausto quer assinalar a mediação entre o princípio da equivalência, constitutivo da circulação simples (M-D-M), e a circulação do capital (D-M-D'), na qual emerge o mais-valor - em última instância, o dinheiro que aparece acrescido no final do processo (D') é o mesmo que reaparece então como dinheiro simples na troca de equivalentes (D). 0 fundamental consistiria em apreender teoricamente a posição do segundo momento no elemento do primeiro, o que implicaria não uma continuidade simples, mas contradição na forma da interversão. Do ponto de vista prático, trata-se do problema da reprodução da não liberdade segundo o princípio válido da liberdade. Essas considerações se tornam cruciais para a concepção de prática de Fausto, religando lógica e política. ${ }^{29}$

28 Não podemos, aqui, entrar nessa discussão, que valeria a pena explorar levando em conta também a crítica de Giannotti a Fausto; para tanto, ver Paulani (1998).

290 que pode ser visto não apenas nas teorias sociais de corte liberal, mas também nas críticas de Fausto tanto ao stalinismo e demais autoritarismos de esquerda ao longo de toda a sua obra quanto às práticas dos assim chamados "melhores" marxismos, bem como ainda ao que ele considerava uma "pseudo-esquerda brasileira" (MLP III, pp.12-42). A partir do final dos anos 1990, Fausto passa da reconstrução lógica para a reconstrução das esquerdas históricas. Marcante nesta trajetória é o seu texto "Sobre a política de Marx", publicado em 1999. Dando como certo "os grandes méritos da crítica marxiana da economia política" (Fausto, 1999, p.30), interessa-nos notar que ali ele formula uma crítica à proibição marxiana de imagens: "A não-posição" do conteúdo político, procedimento "que se destinava a evitar uma interversão" do discurso revolucionário no discurso 


\section{Conclusão}

A interversão diz respeito a um processo que estaria inscrito em todos os movimentos conceituais e históricos que Marx apresenta no contexto da produção capitalista. Assim, ela está relacionada com aquele caráter quasi-metafísico, mas também com uma antinomia que, se não puder ser decifrada como contradição, está fadada a se reproduzir a cada momento segundo um de seus lados, repondo-se infinitamente. Talvez o capitalismo poderia ser então definido como a forma social da interversão, um mecanismo que atua em todos os conteúdos subsumidos a ela. Por essa razão, enfatiza Fausto, "a teoria de Marx acolhe a interversão na sua própria construção; o discurso de Marx se deixa 'arrastar' pela interversão, é atravessado por ela” (MLP I, p.51). Deixando-se levar de modo consciente e atento, em vez de simplesmente sofrê-la ou consagrá-la, Marx apreende a interversão ao mesmo tempo como experiência real e como não verdade.

Em contraposição ao discurso dialético, o discurso do entendimento e dos princípios, trabalhando nos limites da lógica da identidade, de um pensamento de oposições, "cai sem o querer na interversão", cristalizando e repondo "noções cuja única racionalidade - enquanto determinações, consideradas no nível do desenvolvimento do objeto - é a de ser “interversíveis'” (MLP I, p.56). Sobretudo hoje em dia, quando o lugar-comum no pensamento crítico é separar radicalmente lógica objetiva e política, a grande proeza de Ruy Fausto foi tentar reconstruir a dialética como lógica em vista da apreensão rigorosa do não lógico, mais exatamente, da política como dimensão do vivido.

Por mais que os caminhos futuros tenham sido outros, naquele programa de reconstrução ele percebeu que a negligência em relação à dialética ofusca e pode pôr o sentido da prática emancipatória de ponta-cabeça. Essa não é uma possibilidade inerente apenas às teorias liberais da sociedade. Ele também foi consciente do fato de que a dialética serviu de estandarte para experiências monstruosas no século XX.

utópico, "e que por isso era uma condição do discurso crítico, torna-se instrumento dogmático: não se vê mais, ou pelo menos se tem dificuldade em ver, a fraqueza real de um objetivo político que permanece pouco tematizado" (idem, pp.29-30). Fausto enfatiza, então, a necessidade de tematizar diretamente os conteúdos políticos, o que o leva a aludir à distinção entre a noção marxiana de pré-história e a de história natural em Adorno (ver idem, pp.28-29). No tomo I de Marx: lógica e política, ele ainda não havia encontrado uma forma de identificar o fenômeno de posição negativa do ser humano na história, o que ele nomeia, naquele momento, de antihistória, termo que a seu ver caberia melhor do que a noção de pré-história. Já a noção adorniana de história natural mencionada em 1999 serve para preencher essa lacuna de significação que remonta a preocupações de 1983 sobre as insuficiências que ele identifica na ideia de pré-história: “A história do século XX remete, na realidade, à posição do homem - mas à posição negativa do homem. Isto quer dizer que, em certo sentido, se passou à história, mas como advento não da vida genérica, mas da morte genérica, da destruição genérica. Passamos a alguma coisa que é ao mesmo tempo história e pré-história. História na pré-história. Talvez pudéssemos chamá-la de anti-história. Esse fenômeno não foi pensado, prospectivamente, pelo marxismo clássico" (MLP I, p.17). Aprofundar esse novo patamar da reflexão de Fausto abriria um outro capítulo cujo sentido aqui só podemos mencionar. 
Não apreender a interversão pode cobrar o seu preço na moeda da simples negação da liberdade. Daí a centralidade desse processo conceitual objetivo, que, tendose forjado na contradição e na dominação, passaria então a se apresentar cada vez mais no pensamento do autor como uma espécie de princípio de prudência na prática política emancipatória. Seu trabalho reconstrutivo, associando-se no começo às inovações alemãs da nova leitura, queria fazer valer na prática a ideia de que a “dialética é por excelência a lógica do pensamento crítico” (MLP III, p.42).

\section{Referências}

Adorno, T. W. (1995). Einleitung zum „Positivismusstreit in der deustschen Soziologie“. In Gesammelten Schrifen 8: Soziologischen Schriften I (pp.280-353). Frankfurt a.M.: Suhrkamp.

Adorno, T. W. (2003). Vorlesung über Negative Dialektik. Fragmente zur Vorlesung 1965/66. In Tiedemann, R. (Ed.). Nachgelassene Schriften. Abteilung IV: Vorlesungen Bd. 16. Frankfurt a.M.: Suhrkamp.

Backhaus, H-G., Reichelt, H., Schmidt, A., \& et al. (Orgs.). (1974). Gesellschaft. Beiträge zur Marxschen Theorie, n. 1. Frankfurt a.M.: Suhrkamp.

Backhaus, H-G., Reichelt, H. (1995). Wie ist der Wertbegriff in der Ökonomie zu konzipieren? Zu Michael Heinrich: „Die Wissenschaft vom Wert“. In Beiträge zur Marx-Engels-Forschung. Neue Folge, pp. 60-94.

Backhaus, H-G. (1997). Dialektik der Wertform: Untersuchungen zur Marxschen Ökonomiekritik. Freiburg: ça ira.

Backhaus, H.-G. (2021). O núcleo contraditório e monstruoso da formação conceitual da economia política (I). Trad. de Bruno Serrano. Princípios: Revista De Filosofia (UFRN), 28(56), 132-159.

Backhaus, H-G. (2006). Die Kritische Theorie als Forschungsprogramm: „Systematische enzyklopädische Analyse der Tauschabstraktion“. In Jeske, M., Jordan, W. (Ed.). Für einen realen Humanismus: Festschrift zum 75. Geburtstag von Alfred Schmidt (pp.11-38). Bd. 2 (Philosophie in Geschichte und Gegenwart). Frankfurt a.M.: Europaïscher Verlag.

Bellofiore, R., Redolfi Riva, T. (2015). The Neue Marx-Lektüre. Putting the Critique of Political Economy back into the Critique of Society. Radical Philosophy, n. 189, 24-36.

Bonefeld, W. (2014). Critical Theory and the Critique of Political Economy: On Subversion and Negative Reason. London \& New York: Bloomsbury.

Elbe, I. (2010). Marx Im Westen. Die neue Marx-Lektüre in der Bundesrepublik seit 1965. Berlin: Akademie Verlag.

Fausto, R. (1983a). Marx: lógica e política. Investigações para uma reconstituição do sentido da dialética. Tomo I. $2^{\mathrm{a}}$ ed. São Paulo: Editora Brasiliense, 1987.

Fausto, R. (1983b). Os limites do marxismo. [Entrevista concedida a] Folhetim. Folha de S. Paulo, n. 19.730, pp.3-5.

Fausto, R. (1987). Marx: lógica e política. Investigações para uma reconstituição do 
sentido da dialética. Tomo II. São Paulo: Editora Brasiliense.

Fausto, R. (1993). Dialética marxista, dialética hegeliana. O Capital e a Lógica de Hegel. Discurso, n. 20, 41-77.

Fausto, R. (1997). Dialética marxista, dialética hegeliana: a produção capitalista como circulação simples. São Paulo: Paz e Terra.

Fausto, R. (1999). Sobre a política de Marx. Dissenso, n. 2, 19-33.

Fausto, R. (2002). Marx: lógica e política. Investigações para uma reconstituição do sentido da dialética. Tomo III. São Paulo: Ed. 34.

Fausto, R. (2015). Sentido da dialética. Marx: lógica e política (tomo I). Petrópolis: Editora Vozes, 2015.

Grespan, J. (2001). Marx, crítico da teoria clássica do valor. Crítica Marxista, 1 (12), 59-76.

Hegel, G.W.F. (1986). Wissenschaft der Logik I. Bd. 5. Frankfurt a.M.: Suhrkamp.

Hegel, G.W.F. (2017). Ciência da Lógica: 2. A Doutrina da Essência. Trad. Christian G. Iber, Federico Orsini. Petrópolis, RJ: Vozes; Bragança Paulista, SP: Editora Universitária São Francisco.

Heinrich, M. (1999 [1991]). Die Wissenschaft vom Wert: die Marxsche Kritik der politischen Ökonomie zwischen wissenschaftlicher Revolution und klassischer Tradition. Münster: Westfälisches Dampfboot.

Heinrich, M. (2004) An introduction to the three volumes of Karl Marx's Capital. Trad. Alexander Locascio. New York: Monthly Review Press.

Hoff, J. (2009). Marx global: Zur Entwicklung des internationalen Marx-Diskurses seit 1965. Berlin: Akademie Verlag.

Paulani, L. (1998). Ruy Fausto e o pacto com a dialética. In Musse, R., Loureiro, M. I. (Org.), Capítulos do Marxismo Ocidental (pp.209-228). São Paulo: Edunesp.

Marx, K. (1953). Grundrisse der Kritik der Politischen Ökonomie. Berlin: Dietz Verlag.

Marx, K. (1968). Auszüge aus James Mills Buch „Eleménts d'economie politique“. In Marx-Engels Werke, Bd. 40 [=MEW 40] (pp.445-463). Berlin: Dietz Verlag.

Marx, K. (1972). Das Kapital I. In MEW 23. Berlin: Dietz Verlag.

Marx, K. (1982). Ökonomisch-philosophische Manuskripte. In Marx-EngelsGesamtausgabe I/2 [= MEGA] (pp.323-438). Berlin: Dietz Verlag.

Marx, K. (2011). Grundrisse: manuscritos econômicos de 1857-1858: esboços da crítica da economia política. Tradução de Mario Duayer e Nélio Schneider (colaboração de Alice Helga Werner e Rudiger Hoffman). São Paulo: Boitempo.

Marx, K. (2013). O capital: crítica da economia política. Livro I: o processo de produção do capital. Tradução de Rubens Enderle. São Paulo: Boitempo.

Nascimento, R. (2020). Ruy Fausto: A difícil relação entre dialética e política. A terra é redonda. Recuperado de: <https: / / aterraeredonda.com.br/ruy-fausto-adificil-relacao-entre-dialetica-e-politica/>. Acesso em: 20 de nov. 2020.

Reichelt, H. (1982). From the Frankfurt School to Value-Form Analysis. Thesis Eleven, 4 (1), 166-169. DOI: https://doi.org/10.1177/072551368200400111

Reichelt, H. (2002). Die Marxsche Kritik ökonomischer Kategorien. Überlegungen zum 
Problem der Geltung in der dialektischen Darstellungsmethode im „Kapital“. In Fetscher, I., Schmidt, A. (Org.), Emanzipation als Versöhnung. Zur Adornos Kritik der „Warentasuch“-Gesellschaft und Perspektiven der Transformation (pp.142189). Frankfurt a.M.: Verlag Neue Kritik.

Reichelt, H. (2013a). Sobre a estrutura lógica do conceito de capital em Karl Marx. Tradução de Nélio Schneider. São Paulo: Editora da Unicamp.

Reichelt, H. (2013b). Neue Marx-Lektüre. Zur Kritik sozialwissenschaftlicher Logik. Freiburg: ça ira.

Schmidt, A. (1974). Zum Erkenntnisbegriff der Kritik der politischen Ökonomie. In Euchner, W., Schmidt, A. (Org.), Kritik der Politischen Ökonomie heute 100 Jahre „Kapital“. Referate und Diskussionen vom Frankfurter Colloquium 1967 (pp.3048). Frankfurt a. M.: Europäische Verlagsanstalt.

Schmidt, A. (1969). Der strukturalistische Angriff auf die Geschichte. In (Org.), Beiträge zur marxistischen Erkenntnistheorie (pp.194-265). Frankfurt a.M.: Suhrkamp. 